\title{
The Influence of Job Demands on Workplace Bullying Experience among Healthcare Employees
}

\author{
Daniella Mokhtar, Muhammad Farid Arifin Halim \& Norshaffika Izzaty Zaiedy \\ Nor
}

To Link this Article: http://dx.doi.org/10.6007/IJARAFMS/v11-i3/10873 DOI:10.6007/IJARAFMS/v11-i3/10873

Received: 28 June 2021, Revised: 30 July 2021, Accepted: 08 August 2021

Published Online: 29 August 2021

In-Text Citation: (Mokhtar et al., 2021)

To Cite this Article: Mokhtar, D., Halim, M. F. A., \& Nor, N. I. Z. (2021). The Influence of Job Demands on Workplace Bullying Experience among Healthcare Employees. International Journal of Academic Research in Accounting Finance and Management Sciences, 11(3), 223-234.

Copyright: @ 2021 The Author(s)

Published by Human Resource Management Academic Research Society (www.hrmars.com) This article is published under the Creative Commons Attribution (CC BY 4.0) license. Anyone may reproduce, distribute, translate and create derivative works of this article (for both commercial and non-commercial purposes), subject to full attribution to the original publication and authors. The full terms of this license may be seen at: http://creativecommons.org/licences/by/4.0/legalcode

Vol. 11, No. 3, 2021, Pg. $223-234$

Full Terms \& Conditions of access and use can be found at http://hrmars.com/index.php/pages/detail/publication-ethics 


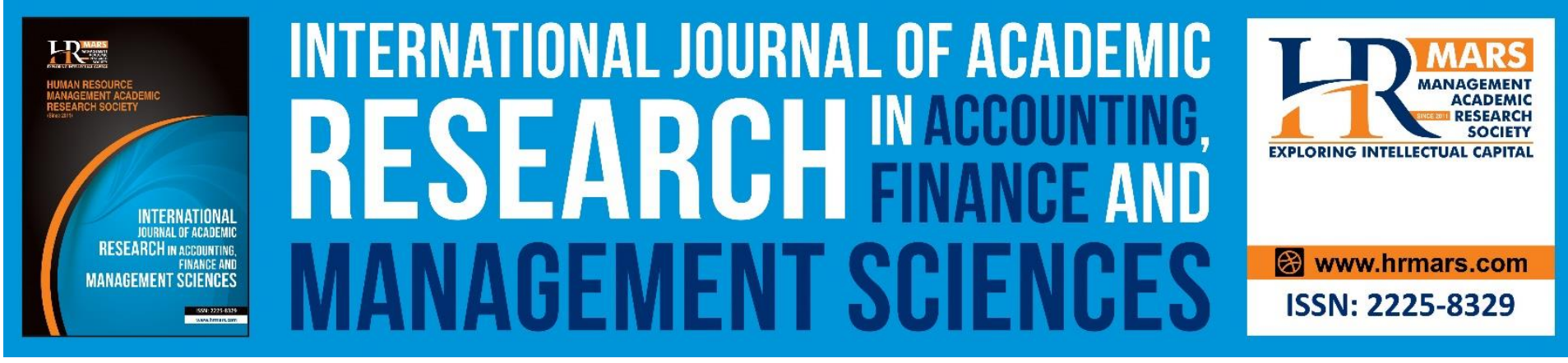

\title{
The Influence of Job Demands on Workplace Bullying Experience among Healthcare Employees
}

\author{
Daniella Mokhtar ${ }^{1}$, Muhammad Farid Arifin Halim² \& \\ Norshaffika Izzaty Zaiedy $\mathrm{Nor}^{3}$ \\ ${ }^{1,3}$ Centre for Research in Psychology and Human Well-being, Faculty of Social Science and \\ Humanities, Universiti Kebangsaan Malaysia, ${ }^{2}$ Emergency and Trauma Unit, Hospital Sultan \\ Haji Ahmad Shah, Pahang \\ Email: daniellamokhtar@ukm.edu.my
}

\begin{abstract}
Healthcare employees are the backbone in helping a country in maintaining the best health performance of all citizens. They have been given the mandate to care and treat patients with professional ethics, however, health employees are not excluded from facing high work pressure from the various demands at work especially in the current times where the nation is struggling with the Covid -19 pandemic. This study sought to examine the prevalence of workplace bullying as well as the level of job demands faced by healthcare employees and its influence on workplace bullying experienced by the employees through a cross-sectional study involving 100 respondents. The Work Stress subscale from Copenhagen Psychosocial Questionnaire (COPSOQ 3) and Negative Act Questionnaire (Einarsen et al. 2009) were used to measure workplace bullying experience and job demands. The data were analysed using Statistical Package for Social Sciences (SPSS) version 25.0. The results of the study found that workplace bullying was prevalent among the respondents especially in regards to workrelated bullying (55\%). Meanwhile quantitative demands, cognitive demands and emotional demands significantly predicted workplace bullying. Work Pace however, did not significantly influence workplace bullying. Further discussions on the findings are reported in the article. Keywords: Quantitative Demands, Work Pace, Cognitive Demands, Emotional Demands, Workplace Bullying, Healthcare Employees.
\end{abstract}

\section{Introduction}

Bullying in the workplace has been a global issue internationally and has been given attention by researchers since the early $90 \mathrm{~s}$. This bullying behavior is likely due to the occurrence of the organization's failure to detect and address such behavior as well as its inability to protect the safety, health, and well -being of employees (Einarsen, Raknes \& Matthiesen, 1994). Thus it is not surprising why bullying behavior in the workplace is three times more common than sexual harassment Namie (2003) besides being placed as the highest factor causing stress received by employees in the workplace (Wilson, 1991). Bullying behavior refers to exposure to negative and systematic forms of behavior that are psychological in nature and researchers 
MANAGEMENT SCIENCES

Vol. 11, No. 3, 2021, E-ISSN: 2225-8329 @ 2021 HRMARS

have agreed that the definition of bullying behavior in the workplace is explained through behaviors such as harassing, offending, isolating from a group or negative actions that can affect one's work.

The negative behavior also involves interactions or processes that occur regularly and recur for at least a week or more than a six-month period. Often the individual who is the target of the bullying has difficulty defending themselves from the negative act. Although adult bullying stduies in Malaysia is scarce, but it has begun to receive attention from researchers in recent years (Hassan et al 2020; Mohd Halim et al. 2018; Mokhtar et al. 2018; 2020). Often, bullying among children are widely researched, due to the behaviours experienced by the victim are usually physical in nature and the effects can be seen more clearly (Leymann 1996). To refer to the situation of bullying in the workplace, Einarsen (1999) has divided bullying behavior into several groups, namely work -related behavior, person -related behavior and physical intimidation. This is evidenced through a preliminary study by Vartia (1991) who found that defamation, social isolation, insinuations against a person's mental health are seen as person -related bullying, while giving too many or too easy tasks and continuously criticizing a person's work refers to behavior work -related bullying. Nevertheless, Leymann (1990) also found that there are also physical threats or physical attacks imposed on the target and this behavior is also categorized as part of the form of aggressive behavior used in the workplace. In addition, bullying behavior that occurs at work is seen differently because the process that takes place is gradual involving psychological attacks in a systematic way and for a long period of time (Giorgi et al., 2013).

The findings of the study also showed that only 10 percent of physical bullying behaviors were recorded making such behaviors difficult to detect (Zapf, 1999). More worryingly, perpetrators make learning objectives as an excuse to commit bullying attacks coupled with the absence of physical injury and even the negative behavior itself is seen as less aware of the victim (Bloisi \& Hoel, 2008). The impact of bullying behavior is not only on the victim but also the organization. Among the impact victims receive as a result of bullying behavior are decreased job satisfaction, disability, difficulty concentrating, difficulty sleeping, and increased negative emotions (anger, depression, frustration, and anxiety) (Einarsen \& Mikkelsen, 2003; Zapf, Knorz \& Kulla, 1996). The effects received by the organization are increased expenditure to train new workforce, absenteeism, increase in intention to leave the organization and also employee turnover (Rayner, Hoel \& Cooper, 2001). Although it is clear that there are serious effects of bullying behavior, but it was found that the lack of studies focused on the factors of bullying behavior which causes the behavior to continue to occur in the workplace, especially in the health sector (Iftikhar \& Qureshi, 2014).

Workplace Bullying Institute reported in 2014 that $27 \%$ of its survey respondents ( $n=$ $137,499,000)$ in America currently experience or have experienced abusive behavior in the workplace. Various complaints and displays in the press were either in print or electronic media. New employees in the health sector (e.g. graduate training medical officers) often has the tendency to be a victim of bullying while at work. In addition, in the face of the Covid-19 pandemic, certainly the workload of health workers have been increasing tremendously. This certainly causes stress and at the same time may encourage bullying behavior to occur. Therefore a study needs to be investigated to find out the current situation of bullying among civil servants working in the health sector in Malaysia. The prevalence of workplace bullying 
MANAGEMENT SCIENCES

Vol. 11, No. 3, 2021, E-ISSN: 2225-8329 @ 2021 HRMARS

among health employees is one of the objectives in this study. The factors contributing to bullying among health and medical workers need to be identified, whether the various job demands (i.e. quantitative, work pace, cognitive and emotional) in the workplace have led to bullying. Thus, this study will sough to examine those objectives.

\section{Research Objectives}

- To examine the level of job demands among healthcare employees

- To examine the prevalence of workplace bullying among healthcare employees

- To examine the influence of job demands on healthcare employees' workplace bullying experience

\section{Literature Review}

Bullying in the workplace is a phenomenon that is emerging widely in research in various disciplines. Reviews found that a concise definition for bullying in the workplace is not available in the literature however it is often categorized as occupational, personal and physically threatening (Einarsen et al., 2009). These behaviors occurring in the workplace can have a negative impact on individuals and organizations. We often hear or read articles related to the story of bullying at school or cyber bullying, but bullying at work is just as important to study. Behaviours that include constant criticism, screaming, exclusions from office meetings and events, overwork, gossip, and even project sabotage are signs of bullying in the workplace. Furthermore, bullying is distinguished by rudeness in the workplace and inappropriate by its intentions and frequency. Bullying in the workplace can also be defined as behaviours that threatens, humiliates, or alienates people in the workplace, or damages their reputation or job performance.

Several different terms or labels are used interchangeably by researchers around the world to describe negative forms of behavior in the workplace such as mobbing (Leymann, 1990; Zapf, Knorz \& Kulla, 1996), harassment (Bjorkqvist et al., 1994), aggression (Baron \& Neuman, 1998) and emotional abuse (Keashly, 2001). The term "workplace bullying" is used primarily by researchers in Australia (Sheehan, 1999), the United Kingdom (Rayner, 1997) and Northern Europe (Einarsen \& Skogstad, 1996). The decision by researchers to use different terms stems from the type of behavior that is reported to occur most frequently in the country where the bullying investigation takes place. In the United States, for example, it largely focuses on incidents of violent workplace behavior (Baron \& Neuman, 1998). While there are variations of precise language used to define bullying in the workplace, there are five most important elements often used to define negative workplace experiences caused by bullying behavior which are (i) the victim has a negative behavioral experience; (ii) the behavior is experienced continuously; (iii) target experiences some effect, either psychological or physical; (iv) the target considers them to have less power than the bully and thus difficult to defend themselves and (v) the target labels themselves as bullied (Rayner \& Keashly, 2004, p. 273).

On the other hand, studies on bullying behavior in Asia, especially in Malaysia, are still lacking. Although the norm in a case of bullying is mostly reported to involve only those groups that belong to the category of bullies, victims, or both, but there are those who are not categorized as bullies or victims of bullying. This group falls into the category of bystanders who are present when the bullying incident took place. Bullying is sometimes said 
MANAGEMENT SCIENCES

Vol. 11, No. 3, 2021, E-ISSN: 2225-8329 @ 2021 HRMARS

to occur between two people without the presence of others. However, this incident can also be witnessed by others. Studies on bullying behavior in Asia have focused more on the impact of workplace bullying especially on well-being and job performance (Gabriele Giorgi, 2010; Hassan, Al Bir \& Hashim, 2015 Iftikhar \& Qureshi, 2014; Qureshi, Rasli \& Zaman, 2014; Yahaya et al., 2012) but less on the factors that contribute to them experiencing the behaviour. Workload or job demand are often reported as a prevalent factor (Baillien et al., 2011; Balducci et al., 2020; Rousseau et al., 2014).

Regardless of the type of behavior that occurs and the level of behavior, researchers and practitioners generally agree that a negative workplace experience can only be defined as bullying if the target of the bullying behavior experiences some form of psychological, emotional or physical threat. Victims of bullying in the workplace may suffer from a variety of physical and psychological symptoms, including stress and anxiety about work, anxiety, fear, depression, loss of confidence, decreased job satisfaction and decreased organizational commitment (Ayoko et al., 2003; Bjorkqvist et al., 1994 ; Einarsen \& Raknes, 1997; Leymann, 1990; Price-Spratlen, 1995; Vartia \& Hyyti, 2002). While the effects of being bullied can vary between individuals, the experience of being bullied often changes a person's life and future. For example, a study investigating bullying behavior at a University of Finland revealed that some participants exhibited symptoms of post -traumatic stress including anxiety, aggression, insomnia, apathy and sociophobia, as a direct result of exposure to bullying (Bjorkqvist et al., 1994, p. 181-1a82). One research shows that people who are bullied typically experience psychological and psychosomatic symptoms at an early stage, just a few months after the bullying begins. Emotional reactions, for example, inability to concentrate and or sleep, emotional changes, anxiety, depression, despair, and fear. Victims describe how they are sometimes unable to find words when expected to speak, lack focus and sometimes lose memory due to not being able to distinguish reality. Psychosomatic symptoms can not only include headaches, gastritis, and sensitivity to sound but can also present as respiratory problems and heart complaints, high blood pressure and pain throughout the body. Initially, the symptoms disappear when the person being bullied is not working, but over time, the symptoms may worsen.

Bullying is regarded as a process instead of a one-time phenomenon. Therefore, victims may cope differently depending on the intensity of the bullying experienced. Research has shown that victims have higher intention to leave compared to non-victims especially when it has impacted their job performance. (Berthelsen et al., 2011). However, emotional intelligence has also been seen as an important factor in moderating job demands and their performance at work (Hatta \& Abdullah, 2020). Even so, it has been reported that victims often remain in the workplace even though they experience bullying due to several factors such as socioeconomic reasons, job scarcity, mobility.

At low levels of bullying, victims adopt passive coping and perceive having more options to go to work voluntarily. Over time, the options for changing work conditions become increasingly limited and work stress can become overwhelming. In the first phase of the bullying process, the person being bullied usually has the possibility to get a good referral, and can apply for and often get other jobs. Still, the victim may be able to be persuaded to not leave a number of reasons. A fixed income guarantee, like most other people, may be important for the person being bullied in to meet his or her cost of living. There may also be 
MANAGEMENT SCIENCES

Vol. 11, No. 3, 2021, E-ISSN: 2225-8329 @ 2021 HRMARS

limited possibilities of finding a position or in a new area away from the bully's area. Moving to another location in some cases is considered impossible, due to the fact that the victim of bullying lives close to a sick or elderly relative who needs support and help. He can also live in a remote area, where there are few vacancies available. For these reasons, the bullied person is prevented from leaving his or her current job acquiring a suitable position elsewhere. Seeing this situation, the victim prefers to hide their emotions rather than confront because they might realizes the efforts they make may be futile (Berry et al., 2016).

\section{Research Method \\ Design and Sample}

The study adopted a cross-sectional approach using quantitative measures that was conducted fully only due to the restrictions of face-to-face meetings. The questionnaire consisted of validated scales that went through a back translation process to the Malay Language. Instructions were provided and individual's consent were asked the beginning of the study. Respondents were able to fill in the questionnaire at their own pace and they were given contact details of the head researcher for any inquiries. Respondents were recruited via purposive sampling from a medical institution in Pahang, Malaysia in which they had to meet the a list of criteria in order to be eligible for the study. The criteria were (i) working as front line employee in the health sector, (ii) Malaysian citizen (iii) able to read and understand Malay (iv) have worked at least one year with the current organisation. A total of 100 respondents were recruited which consist of equal gender distribution male (50\%) and female (50\%) with majority of the sample were among the Malay Ethnic (93\%). From the total sample more than half (62\%) were between age 20 to 30 years old, 33\% were married and one third of the sample (33\%) had one to five years of work experience.

\section{Instrument}

Work Stress

Work Stress was measured using 14 items adopted from the Third Version of the Copenhagen Psychosocial Questionnaire (COPSOQ-3) that was developed by Kristensen et al. (2007). The subscale consisted of four dimensions to Quantitative Demands (4 items), Work Pace (3 items), Cognitive Demands ( 4 items) and Emotional Demand ( 3 items). All items were positive, and response were based on a 5-Likert scale ranging from (1) Strongly Disagree to (5) Strongly Agree. An example item of Quantitative Demands is "Is your workload unevenly distributed so it piles up?" while Work Pace is "Do you have to work very fast?". An example item of Cognitive Demands is "Does your work require that you remember a lot of things?" while Emotional Demand is "Is your work emotionally demanding?".

\section{Workplace Bullying}

Work Bullying was measured using the Revised version of Negative Act Questionnaire (NAQ$\mathrm{R})$ that was developed by Einarsen et al. (2009). The scale consist of 21 items measuring three dimensions which are Work-Related (7 items), Person-Related (11 items) and Physical Intimidation ( 3 items). All items were positive, and response were based on a 5-Likert scale ranging from (1) Never to (5) Daily. An example item of Work-Related is "Is your workload unevenly distributed so it piles up?", Person-Related is "Do you have to work very fast?" while an example item of Physical Intimidation is "Does your work require that you remember a lot of things?". 
MANAGEMENT SCIENCES

Vol. 11 , No. 3, 2021, E-ISSN: 2225-8329 @ 2021 HRMARS

\section{Analysis}

Analysis was carried out using the Statistical Packages for Social Sciences (SPSS) Software. Descriptive analysis was performed to look at frequencies and descriptive values while inferential statistics were used to look at prediction values between the variables in the study.

\section{Findings}

The following table describes the frequency of each sub-dimensions of work stress which are Quantitative Demands, Work Pace, Cognitive Demands and Emotional Demands. All four variables were categorized according to three levels: low, moderate and high. The results are shown in the table below:-

Table 1: Frequency Levels of the Sub-dimensions of Job Demands ( $N=100)$

\begin{tabular}{lccc}
\hline \multicolumn{1}{c}{ VARIABLE } & LEVEL & FREQUENCY & PERCENTAGE (\%) \\
\hline Quantitative Demands & Low & 27 & 27.0 \\
& Moderate & 73 & 73.0 \\
& High & 0 & 00.0 \\
Work Pace & Low & 26 & 26.0 \\
& Moderate & 62 & 62.0 \\
& High & 12 & 12.0 \\
Cognitive Demands & Low & 22 & 22.0 \\
& Moderate & 53 & 53.0 \\
& High & 25 & 25.0 \\
Emotional Demands & Low & 58 & 58.0 \\
& Moderate & 38 & 38.0 \\
& High & 4 & 4.0 \\
TOTAL & & 100 & 100 \\
\hline
\end{tabular}

Table 1 displays the frequency level of the four sub-dimensions of work stress among the respondents in this study. Majority of the samples (73\%) scored average in terms of quantitative demands, $62 \%$ scored average in terms of work pace, $53 \%$ reported moderate cognitive demands and slightly more than half (58\%) reported low in emotional demands. However, between the four dimensions of job demands, cognitive demands has more respondents coring high (25\%), followed by work place (12\%) and emotional demands (4\%).

Table 2 presents the frequency levels of bullying exposure among the 100 respondents that participated in the study. Respondents who experienced at least one negative act on a weekly or daily basis were categorised as victims of bullying. For those who experienced any negative acts on rare occasions, or a monthly basis were categorised as mistreated while those who did not experience any of the negative acts at all were categorised as non-exposed. Results show that majority of the respondents were exposed to work-related bullying (55\%) followed by person-related (23\%) and only $4 \%$ were victims of physical intimidation. Almost half of the respondents were either mistreated via work-related bullying behaviours (41\%) or person- 
INTERNATIONAL JOURNAL OF ACADEMIC RESEARCH IN ACCOUNTING, FINANCE AND

MANAGEMENT SCIENCES

Vol. 11, No. 3, 2021, E-ISSN: 2225-8329 @ 2021 HRMARS

related bullying behaviours (49.6\%) and more than a third were mistreated by physical intimidating behaviours (36\%).

Table 2: Descriptive Statistics for Exposure to Bullying ( $N=100)$

\begin{tabular}{lcccc}
\hline \multicolumn{2}{l}{ Variables } & Mean (S.D) & \multicolumn{3}{c}{ Frequency (\%) } \\
\cline { 1 - 3 } Workplace Bullying & & Non-exposed & Mistreated & Victims \\
\cline { 3 - 5 } Work Related & $17.43(6.45)$ & $4(4.0)$ & $41(41.0)$ & $55(55.0)$ \\
Person Related & $18.94(10.35)$ & $28(28.0)$ & $49(49.0)$ & $23(23.0)$ \\
$\begin{array}{l}\text { Physical } \\
\text { Intimidation }\end{array}$ & $4.36(2.18)$ & $59(59.0)$ & $36(36.0)$ & $5(5.0)$ \\
\hline
\end{tabular}

The following table (Table 3) presents the result of the multiple regression analyses that was used to test the prediction values of work stress dimensions onto workplace bullying dimensions.

Table 3: Job Demands Predicting Mental Health of Health Workers

\begin{tabular}{lccccccccc}
\hline \multirow{2}{*}{ Item } & \multicolumn{3}{c}{ Work-Related } & \multicolumn{3}{c}{ Person-Related } & \multicolumn{3}{c}{ Physical Intimidation } \\
\cline { 2 - 10 } & $\mathrm{B}$ & $\mathrm{SE}$ & $\mathrm{B}$ & $\mathrm{B}$ & $\mathrm{SE}$ & $\beta$ & $\mathrm{B}$ & $\mathrm{SE}$ & $\beta$ \\
\hline Quantitative & 1.28 & .28 & $.38^{* * *}$ & 1.79 & .52 & $.32^{* *}$ & .42 & .10 & $.36^{* * *}$ \\
Work Pace & .05 & .23 & .02 & .67 & .43 & .17 & -.06 & .09 & -.07 \\
Cognitive & .48 & .17 & $.27^{* *}$ & -.06 & .32 & -.02 & .04 & .07 & .06 \\
Emotional & .63 & .22 & $.28^{* *}$ & 1.20 & .41 & $.33^{* *}$ & .32 & .08 & $.41^{* * *}$ \\
$\mathrm{R}^{2}$ & & .536 & & & .398 & & & .429 & \\
$\mathrm{~F}$ & \multicolumn{3}{c}{$29.61^{* * *}$} & & & $15.69^{* * *}$ & & & $19.58^{* * *}$ \\
\end{tabular}

Note. ${ }^{*} \mathrm{p}<.05, * * \mathrm{p}<.01, * * * \mathrm{p}<.001$

Multiple regression analysis was conducted with job demands as the predictors and workplace bullying as the dependent. The summary of the analysis is shown in Table 3 . The results of the regression showed that between the four subdimensions of job demand, quantitative demand and emotional demand significantly influenced all dimensions of workplace bullying where quantitative demand predicted work-related bullying $(\beta=.38$, $p<.001)$, person-related bullying $(\beta=.32, p<.01)$ and physical intimidation $(\beta=.36, p<.001)$. Meanwhile emotional demand predicted work-related bullying $(\beta=.28, p<.01)$, personrelated bullying $(\beta=.33, p<.001)$ and physical intimidation $(\beta=.41, p<.001)$. Findings also show that work pace did not influence any of the workplace bullying dimensions while cognitive demand only significantly predicted work-related bullying $(\beta=.27, p<.01)$ but not for the other two subdimensions. The predictors influenced $53.6 \%$ of variance $\left(R^{2}=.536, F\right.$ $(4,95)=29.61, p<.001)$ for the work-related model, 39.8\% of variance $\left(R^{2}=.398, F(4,95)\right.$ $=15.69, p<.001)$ for the person-related model and $42.9 \%$ of variance $\left(R^{2}=.429, F(4,95)\right.$ $=19.58, p<.001$ ) for the physical intimidation model. 


\section{Discussion}

Findings of the study showed that between the four dimensions of job demands, health employees faced higher cognitive demands followed by work place and emotional demands. Although the employees are affected directly (in terms of workload) due to the pandemic, majority seem to perceive their quantitative demands as moderate. In terms of its prevalence, victims reported having to experience more work-related bullying behaviours and only a handful reported being victims of physical intimidations. Nevertheless, almost half of the total sample had experiences some sort of mistreatment in all three behaviours (work-related, person-related and physical intimidation) which shows that these behaviours are prevalent in the healthcare setting. According to the conflict escalation hypothesis, bullying is a process triggered by a conflict that, when poorly managed or unsatisfactorily resolved, can lead to personal attacks to destroy the reputation of the other party, which, after a series of failed attempts to cope with bullying behaviours, may experience severe trauma (Zapf and Gross, 2001). This is a good illustration on how disagreement on issues can gradually shift to bullying. The process usually starts off following a disagreement on issues which then turns to something personal. For example, the conflict might be work-related at the beginning, but when left unresolved or prolonged, shifts to something person-related. It starts off by negative acts which are normally discreet in nature and as the conflict develops, it moves on to acts that are more aggressive where actions are often expressed in a direct form. Bullying then begins once the negative acts are constantly repeated towards one of the parties and they find it hard to defend themselves against it.

In terms of job demand predictions, quantitative demands and emotional demands significantly influences all dimensions of workplace bullying. Although quantitative demands faced reported by sample in this study was mostly moderate, but findings show that it was a strong predictor of workplace bullying. As for emotional demand, one possible explanation could be that healthcare employees often have to deal with extreme emotions, and are often front liners to the healthcare institutions. This can be observed as a customer-employeemanagement triangle. Health employees have the pressure to maintain a customer-focused service and the message of continuously improving performance is always being conveyed. It is necessary that good customer service is maintained even when there are limitations in terms of resources and costs. Therefore, frontline employees play an important role in responding to customers through their formal roles (Cenatiempo, George and Casey, 1997). Employees having frequent face-to-face or voice-to-voice interactions with customers played a critical role in emotional dissonance (Karatepe and Aleshinloye, 2009). Since the continued success of an organisation depends on providing a quality services to customers, the question arises over the extent to which service organisations use customer orientation in service work to force front liners to accept negative work conditions in general. As previous studies have shown, employees working in the frontline are more inclined to experience emotional dissonance (Phillips et al., 2007). This might be caused by the nature of their job which requires frequent interaction with customers and they are expected to behave in a certain sway which maintains an 'organisationally-desired emotion' during interpersonal transactions.

Having a small sample may cause sampling errors and less sensitivity in analysis besides not having able to generalise the outcomes. Although a sample size of 100 people was sufficient to test the hypotheses of the study, a larger sample size would provide stronger 
MANAGEMENT SCIENCES

Vol. 11, No. 3, 2021, E-ISSN: 2225-8329 @ 2021 HRMARS

support to the findings in this study. The number of questions (a total of 50) may have also caused reservation from respondents especially among employees with limited time to answer, or may cause them to answer the survey questions in a rush. Another limitation to the study was mobility due to the movement restrictions imposed as the effect of the Covid19 outbreak. This has made it difficult to distribute questionnaires face-to-face and were only made through social media sites and link distribution. For future improvement, this study suggests that the sample size can be increased so that sampling errors can be reduced and in turn form more accurate findings. It is suggested that it may be possible to use Krecjie \& Morgan (1970) sample size measurements that match the sample size and the study population size. In addition, this study can be conducted on other professions. Researchers can extend it further to other professions to assess the level of work stress and bullying behavior while working and not just focus on health workers alone.

\section{Conclusion}

There has been a growing interest on the study of workplace bullying among front line employees in the health sector especially in recent years where the pandemic COVID-19 has struck globally. Health employees are the backbone in helping a country in maintaining the best health performance of all citizens. They have been given the mandate to care and treat patients with professional ethics, however, health employees are not excluded from facing high work pressure from the various demands at work especially in the current times where the nation is struggling with the Covid -19 pandemic. This study has answered the questions and objectives of the study where as a whole this study succeeded in dissecting the level of stress in the workplace of health employees although the findings are not generalizable. This study opens a new platform to study in more depth on the factors that predicts bullying behaviour in the workplace. To conclude, it is hoped that more studies will be conducted in the future to study the level of well -being that are not just limited to health employees in particular and by taking into account the improvement suggestions that have been described.

\section{Reference}

Hatta, A. M., \& Abdullah, N-A. (2020). The role of emotional intelligence in work stress and work performance. International Journal of Academic Research in Business \& Social Sciences $10: 274-291$

Balducci, C., Baillien, E., Broeck, A. V. D., Toderi, S., \& Fraccaroli, F. (2020). Job demand, job control, and impaired mental health in the experience of workplace bullying behavior: a two-wave study. International journal of environmental research and public health, 17(4), 1358.

Baillien, E., De Cuyper, N., \& De Witte, H. (2011). Job autonomy and workload as antecedents of workplace bullying: A two-wave test of Karasek's Job Demand Control Model for targets and perpetrators. Journal of occupational and Organizational Psychology, 84(1), 191-208.

Bashir, A., Hanif, R., \& Nadeem, M. (2014). Role of personal factors in perception of workplace bullying among telecommunication personnel. Pakistan Journal of Commerce and Social Sciences (PJCSS), 8(3), 817-829.

Berthelsen, M., Skogstad, A., Lau, B., \& Einarsen, S. (2011). Do they stay or do they go? A longitudinal study of intentions to leave and exclusion from working life among targets of workplace bullying. International Journal of Manpower, 32 (2), 178 - 193 
MANAGEMENT SCIENCES

Vol. 11, No. 3, 2021, E-ISSN: 2225-8329 ๔ 2021 HRMARS

Björkqvist, K., Österman, K., Hjelt-Bäck, M. (1994). Aggression among university employees. Aggressive Behaviour,20:173-84.

Cairns, R. B., Cairns, B. D., Neckerman, H. J., Gest, S., dan Gariepy, J. L. (1988). "Peer Networks and Aggressive Behavior: Social Support or Social Rejection?" Developmental Psychology, 24, 815-823.

Cenatiempo, A., George, T., \& Casey, A. (1997). The Role of Front-Line Employees in Knowledge Creation : a Case Study of a Federal Government Agency.

Rayner, C., Hoel, H., \& Cooper, C. (2001). Workplace bullying: What we know, who is to blame and what can we do?. CRC Press.

Einarsen, S., \& Skogstad, A. (1996). Bullying at work: Epidemiological findings in public and private organizations. European journal of work and organizational psychology, 5(2), 185-201.

Einarsen, S., \& Raknes, B. I. (1997). Harassment in the workplace and the victimization of men. Violence and victims, 12(3), 247-263.

Farrington, D. P. (1993). Understanding and preventing bullying. In M. Tonry (Ed.), Crime and Justice, Chicago: University of Chicago, Vol. 17, pp. 381-458.

Groeblinghoff, D., \& Becker, M. (1996). A case study of mobbing and the clinical treatment of mobbing victims. European journal of work and organizational psychology, 5(2), 277294.

Giorgi, G. (2009). Workplace bullying risk assessment in 12 Italian organizations. International Journal of Workplace Health Management.

Hassan, A., Al Bir, A. T. S., \& Hashim, J. (2015). Workplace bullying in Malaysia: Incidence, consequences and role of organisational support. In Innovation, Finance, and the Economy (pp. 23-35). Springer, Cham.

Hoel, H., Einarsen, S., Zapf, D., Vartia, M., \& Cooper, C. L. (2003). Empirical findings of bullying in the workplace. In Bullying and Emotional Abuse in the Workplace: International Perspectives in Research and Practice. Taylor \& Francis.

Iftikhar, M., \& Qureshi, M. I. (2014). Modeling the workplace bullying the mediator of workplace climate-employee health relationship. Journal of Management Info, 4(1), 96124.

Karatepe, O. M., \& Aleshinloye, K. D. (2009). Emotional dissonance and emotional exhaustion among hotel employees in Nigeria. International Journal of Hospitality Management, 28(3), 349-358. https://doi.org/10.1016/j.ijhm.2008.12.002

Kivimäki, M., Elovainio, M., \& Vahtera, J. (2000). Workplace bullying and sickness absence in hospital staff. Occupational and Environmental Medicine, 57(10), 656-660.

Leymann, H. (1996). The content and development of mobbing at work. European journal of work and organizational psychology, 5(2), 165-184.

Leymann, H. (1990). Mobbing and psychological terror at workplaces. Violence and victims, 5(2), 119-126.

Halim, H. A. M., Halim, F. W., \& Khairuddin, R. (2018). Does Personality Influence Workplace Bullying and Lead to Depression Among Nurses?. Jurnal Pengurusan , 53.

Mokhtar, D., Adnan, H. A., \& Roshaizad, N. A. (2018). The correlates of workplace bullying on employees' health and well-being among frontline employees. Jurnal Psikologi Malaysia, 32(4).

Mokhtar, D., Hassan, N., \& Abdullah @ Mohd. Nor. H. (2020). Coping with Workplace Bullying among Front line employees: A cross-sectional study. International Journal of Psychosocial Rehabilitation, 24(4), $4238-4251$ 
Namie, G. (2003). Workplace bullying: Escalated incivility. Ivey Business Journal, 68(2), 1-6.

Hassan, N., Kendrick, A., \& Mokhtar, D. (2020). Bullying and its four functions: a study of young offenders in juvenile justice institutions. International Journal of Psychosocial Rehabilitation 24 : 4207-4223

Osif, B. A. (2010). manager's bookshelf: Workplace Bullying. Library Leadership \& Management, 24(4), 206-212.

Rousseau, M. B., Eddleston, K. A., Patel, P. C., \& Kellermanns, F. W. (2014). Organizational resources and demands influence on workplace bullying. Journal of Managerial Issues, 286-313.

Salin, D. (2003). Ways of explaining workplace bullying: A review of enabling, motivating and precipitating structures and processes in the work environment. Human relations, 56(10), 1213-1232.

Seki, Y. (2008). Working condition factors associated with time pressure of nurses in Japanese hospitals. Journal of occupational health, 50, 181 -190.

Twale, D. J., \& De Luca, B. M. (2008). Faculty incivility: The rise of the academic bully culture and what to do about it (Vol. 128). John Wiley \& Sons.

Yahaya, A., Ing, T. C., Yahaya, N. \& Boon, Y. (2012). The Impact of Workplace Bullying towards Work Performance. Archive Des Science, 65(4), 18 -28.

Zapf, D. (1999). Organisational, work group related and personal causes of mobbing/bullying at work. International journal of manpower, 20(1/2), $70-85$

Zapf, D., \& Gross, C. (2001). Conflict escalation and coping with workplace bullying: A replication and extension. European Journal of Work and Organizational Psychology, 10(4), 497-522. https://doi.org/10.1080/13594320143000834

Zapf, D., Knorz, C., \& Kulla, M. (1996). On the relationship between mobbing factors, and job content, social work environment, and health outcomes. European Journal of work and organizational psychology, 5(2), 215-237. 